\title{
¿QUIÉN ES EL SIERVO FIEL Y
PRUDENTE?
}

Hanco Torres, Jesús Universidad Peruana Unión Jesushanco@teologia.edu.pe

Fecha de recepción: Junio 2014

Fecha de aceptación y versión final: Junio 2014

Texto base: Mateo 24:45-51

Proposito general: Mayordomía

Palabra clave: Administrar

\section{Introducción}

- Ilustración: Era la última semana de Jesús antes de su crucifixión y se encontraba en el Monte de los olivos, después de hablar a la multitud, sus discípulos tomándole aparte le hicieron algunas preguntas: ¿cuándo serán estas cosas? ¿qué señal habrá de tu venida, y del fin del siglo? Ahora Jesús se encontraba hablando solo a sus discípulos, en un círculo más familiar, les advirtió sobre las señales que acontecería antes de su venida. Y luego al describirles su venida, comenzó a hablarles por medio de ilustraciones que tenían la intención de ayudar a entender una lección importante: la preparación personal del cristiano para el retorno prometido de Jesús. Así, Jesús les relató la parábola de 
la higuera, de Noé, del ladrón y ahora se proponía a hablarles otra parábola, otra narración que ilustraría otra verdad importante para sus discípulos y para su iglesia.

- Propósito: El mensaje de hoy tiene por propósito: Mostrar la responsabilidad que tiene el cristiano de ser un administrador fiel de todos los dones dados por Dios y prepararse para el retorno prometido de Cristo. Vamos a orar antes de abrir la Palabra de Dios. (oración)

- Texto Bíblico: Leamos el texto de Mateo 24: 45-51.

I. Bienaventurado al siervo fiel y prudente, a quien su Señor le halle trabajando (24:45-47)

1. Jesús acaba de culminar la parábola del ladrón, lanzando una verdad: "Estad preparados; porque el Hijo del Hombre vendrá a la hora que no pensáis".

2. Han pasado alrededor de 1983 años desde que Jesús retornó al cielo, allá por el año 31 d.C. Es interesante notar cómo dentro de nuestra iglesia, el énfasis con el cual se predicaba acerca de la 2 da venida de Cristo a este mundo, se ha ido apagando. Y en la actualidad, sabemos que Cristo va a venir, pero, muchos creemos que aún falta mucho. Es allí cuando necesitamos recordar el mensaje de Cristo: "prepárate porque vendré a la hora que tú no piensas"(la cursiva es del autor).

3. Es entonces cuando Pedro, interrumpe y pregunta: Señor, ¿dices esta parábola a nosotros, o también 
a todos? (Luc. 12:41). Cristo responde a su amado discípulo con una pregunta: “Quién es, pues, el siervo fiel y prudente, al cual puso su señor sobre su casa para que les dé el alimento a tiempo?" Jesús desea ilustrar la verdad sobre la preparación para la venida de él a través de la analogía de un esclavo que es colocado por su Señor en el cargo de mayordomo. Uno de los ejemplos más conocidos dentro de la Biblia es el de José, quien fue mayordomo sobre toda la casa de Potifar.

4. El mayordomo era el responsable de una propiedad o negocios de otra persona. En la actualidad podríamos llamar como gerente. En aquellos tiempos el mayordomo administraba tanto los bienes materiales como humanos (el cuidado de estaban bajo la responsabilidad del mayordomo.

5. Sin embargo, había dos cosas que ese siervo nunca debía olvidar, (1) El no era dueño de nada de lo que estaba recibiendo, él había sido colocado solo como un encargado de toda aquella casa, gracias a su Señor. (2) Él era responsable de todas las cosas, de las cuales daría cuenta al dueño cuando éste retornase. El texto dice: "para que les dé el alimento a tiempo", la tarea de alimentar a su debido tiempo a la casa muestra un cuidado muy especial que debía tener el siervo hacia cada una de las cosas que se le había encargado (los demás esclavos, animales y demás pertenencias del amo), semejante a la de un progenitor.

6. Cristo pregunta por un siervo fiel y prudente y además añade: "Bienaventurado aquel siervo al cual, cuando su señor venga, le halle haciendo así” (ver. 46). Jesús describe la alegría y el gozo que 
espera al mayordomo fiel y prudente, que cumple con lo encomendado por su Señor.

7. Cristo añade una promesa adicional para aquel siervo, y es que su Señor le pondrá sobre "todos sus bienes". Ya no solo sobre su casa, sino sobre todas sus pertenencias (vers. 47). Todo esto acontecería al siervo cuando su Señor llegue y le halle cumpliendo con su responsabilidad.

8. Aplicación: Hoy en día, existe un tendencia a creer que todo lo que tenemos: habilidades, dinero, títulos y nuestro mismo cuerpo, nos pertenece y que podemos hacer con él, lo que nosotros queramos, llegando a olvidar nuestra responsabilidad ante Dios (Deut. 8:11, 17, 18).

9. Al igual que el siervo de la parábola, necesitamos recordar: (1) Nosotros no somos dueños de nada de lo que tenemos, somos tan solo mayordomos, administradores, gerentes de todas aquellas cosas. Por lo cual, todos nuestros bienes materiales, tiempo, dinero, habilidades y aun nuestro mismo cuerpo le pertenece a Dios y (2) Somos responsables delante de Dios de cómo estamos administrando cada una de las cosas que Dios nos ha encargado, quizá la pregunta sería ¿cómo estoy administrando el cuerpo que Dios me encargó? ¿cómo estoy administrando los bienes que él me otorgó? ¿cómo estoy administrando los talentos y habilidades que él me confirió?

10. Cristo profiere una gran bendición (bienaventurado que en griego significa: feliz, bendito, afortunado, dichoso) para todo aquel siervo que cuando Cristo vuelva le encuentre administrando sabiamente 
todo lo que le ha encargado. Todo esto ocurrirá cuando Cristo venga y pida cuenta a cada uno de sus siervos.

\section{Cruel castigo para el siervo malo, a quien su señor le halle golpeando a sus semejantes y viviendo disipadamente $(24: 48-51)$}

1. Ahora Jesús, dentro de su parábola presenta una condicional, Pero, qué pasaría si aquel siervo malo dijere en su corazón: "Mi Señor tarda en venir", cuán oportuno es ver esta posibilidad, aquel siervo que en lugar de ser fiel y prudente, es calificado como siervo MALO. Un siervo que recibe los privilegios y la responsabilidad. Sin embargo, Jesús presenta a este siervo calificado de "malo" diciendo en su corazón, es decir en lo más íntimo de sus pensamientos: "Mi Señor tarda en venir".

2. Fijémonos que este siervo es consciente de que su Señor va a venir, no niega la venida de su Señor. Y más aún lo considera como "su Señor" (vers. 48). Sin embargo, su modo de vida, muestra todo lo contrario. Este siervo reconoce al dueño de todas las cosas, y le considera como "su Señor", pero en lo profundo de sus pensamientos cree que su Señor todavía tardará mucho en venir. Es decir no considera necesario prepararse porque está seguro que su Señor vendrá muchísimo más tarde.

3. A este pensamiento interno, que sale del corazón de aquel siervo, Jesús añade dos acciones: (1) Comienza a golpear a los siervos, y (2) a comer y beber con los borrachos. Cuán importante es recordar el 
texto Mar 7:21: "del corazón de los hombres, salen los malos pensamientos, los adulterios, las fornicaciones, los homicidios,... etc."

4. Sin duda, el corazón de este siervo, sus pensamientos más profundos, estaban lejos de anhelar el encuentro con su Señor. Estos le condujeron a alejarse más y más de la responsabilidad que se le había encomendado.

5. Su tarea era "dar alimento a los siervos de la casa", pero contrario a ello, él comienza a golpearlos. Abandona su tarea, su responsabilidad, deja todo lo que su Señor le había pedido que administrara y lleva una vida bohemia y despreocupada de la tarea encomendada.

6. Jesús continúa con la parábola, mencionando la venida del Señor de aquel siervo, pero en el día y la hora que no le espera. Es importante notar que la venida de Cristo será sorpresiva e inesperada solamente para quienes no viven en acuerdo a la palabra de Dios. Los hijos de Dios no están en tinieblas sobre la venida de Cristo (1 Tes. 5:4).

7. Aun cuando en el texto griego, dice literalmente "le partirá en dos" o "le cortará en pedazos", aquí la Biblia muestra que el castigo para este siervo sería extremadamente severo. Y además de ello, la parte de este siervo, es decir su herencia o las cosas que le pertenecían sería colocada con los hipócritas.

8. Hacía horas atrás que Jesús había empleado esta palabra "hipócritas" al referirse a los fariseos y escribas (Mat 23: 23, 25, 27, 29, 51). Personas que conocían bastante de la Palabra de Dios pero que no daban un correcto testimonio de fidelidad íntegra, sino 
solamente una vida de apariencia externa. Una lucha por fingir delante de otras personas mucha fidelidad a Dios, en contraste con un corazón totalmente alejado de Dios (Mat. 23:27).

9. La parábola finaliza con la frase "allí será el lloro y el crujir de dientes" frase utilizada en diversas ocasiones por Mateo para presentar el remordimiento, la angustia y el sufrimiento de quien al final fue hallado falto.

10.Aplicación: Puede ser que nosotros no neguemos a Dios, pero en lo más íntimo de nuestro corazón pensamos y deseamos que Cristo demore un poco más. Esto debido a que nuestro tesoro y anhelos más principales están en esta tierra.

11.Puede ser que quizá, estemos tomando nuestras habilidades y talentos, posición social, cargos o nuestra misma fisonomía y demás privilegios que Dios nos ha otorgado, para menospreciar a otra persona, para rebajarla porque quizá no tiene un puesto como el nuestro o talentos como nosotros los tenemos.

12. O tal vez estemos viviendo una vida disipada, una vida doble, el sábado en la iglesia pero en el resto de la semana lejos de Dios. Olvidando la gran tarea que nuestro Señor nos ha encomendado. De poder cuidar de su casa: ser un mayordomo fiel.

\section{Conclusión y llamado}

1. A través de la Biblia podemos encontrar siempre dos camino: el camino de la obediencia y el de la desobediencia, uno ancho y el otro angosto, los cuales con- 
ducen a dos finales: la vida eterna y la destrucción eterna.

2. El Señor nos invita hoy: (1) Recordar que todo le pertenece a él y nada de lo que tenemos como "propiedad" en este mundo es nuestro, pues todo es de Dios. Él es el Señor de todo, hasta de nuestros propios cuerpos (2) Dios vendrá un día a pedir cuentas de qué hemos hecho con el tiempo, los talentos, los bienes materiales y el propio cuerpo que nos ha otorgado. Para algunos esto será un encuentro grato y bendecido. Pero para otros será una sorpresa muy triste y vergonzosa.

3. Pero, el mensaje de hoy se centra en la pregunta de Cristo: ¿quién es pues el siervo fiel y prudente? (Mat 24:45) Si quizá hemos estado marchando por rumbo equivocado, Cristo nos invita a reflexionar en esta pregunta y levantarnos diciendo: Señor, quiero ser aquel siervo fiel y prudente, ayúdame a vivir una vida de servicio y de fidelidad a ti y a todo lo que me das el privilegio de administrar

\section{Oración.}




\section{GUÍA DE TRANSLITERACIÓN PARA CARACTERES HEBREOS Y GRIEGOS}

Consonantes y vocales equivalentes para los caracteres hebreos:

\begin{tabular}{|c|c|c|c|c|}
\hline 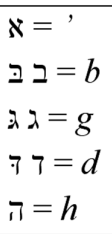 & $\begin{array}{l}i=w \\
i=z \\
i=j \\
ט=t \\
י=y\end{array}$ & 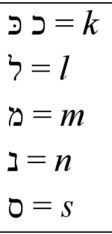 & $\begin{array}{l}\mathrm{y}=` \\
פ=p \\
פ=f \\
\mathrm{y}=t s \\
\vec{P}=q\end{array}$ & $\begin{array}{l}\text { ר }=r \\
\dot{W}=s \\
\dot{U}=s h \\
ת=t \\
ת=t h\end{array}$ \\
\hline $\begin{array}{l}\text { ? }=a \\
=\bar{a} \\
\text { ? }=a\end{array}$ & $\begin{array}{l}\text { Y } e \\
\text { @= }=\hat{e} \\
=e\end{array}$ & $\begin{array}{l}=i \\
=\hat{\imath}\end{array}$ & $\begin{array}{l}\dot{y}=0 \\
\dot{r}=\boldsymbol{o} \\
\cdot \mathfrak{i}=\hat{\boldsymbol{o}}\end{array}$ & $\begin{array}{l}\imath=\hat{u} \\
\mathrm{\imath}=u\end{array}$ \\
\hline
\end{tabular}

Consonantes y vocales equivalentes para los caracteres griegos:

\begin{tabular}{|l|l|l|l|l|}
\hline$\alpha=a$ & $\eta=\bar{e}$ & $v=n$ & $\tau=t$ & $\ddots=h$ \\
$\beta=b$ & $\theta=t h$ & $\xi=x$ & $v=y$ & $\rho=r h$ \\
$\gamma=g$ & $1=i$ & $0=o$ & $\varphi=p h$ & $\gamma \chi=n j$ \\
$\delta=d$ & $\kappa=k$ & $\pi=p$ & $\chi=c h$ & $\gamma \xi=n x$ \\
$\varepsilon=e$ & $\lambda=l$ & $\rho=r$ & $\psi=p s$ & $\gamma \kappa=n k$ \\
$\zeta=z$ & $\mu=m$ & $\sigma \varsigma=s$ & $\omega=\bar{o}$ & $\gamma \gamma=n g$ \\
\hline
\end{tabular}

